\title{
Model for the origin, ascent, and eruption of lunar picritic magmas
}

\author{
Malcolm J. Rutherford ${ }^{1, *}$, James W. Head ${ }^{1}$, Alberto E. Saal ${ }^{1}$, \\ Erik Hauri ${ }^{2}$, and Lionel Wilson ${ }^{3}$
}

\author{
${ }^{1}$ Department of Geological Sciences, Brown University, Providence, Rhode Island 02912, \\ U.S.A. \\ ${ }^{2}$ Department of Terrestrial Magnetism, Carnegie Institution of Washington, Washington, \\ D.C. 20015, U.S.A.
}

${ }^{3}$ Lancaster Environment Center, Lancaster University, Lancaster LA1 4YQ, U.K.

\begin{abstract}
A model for the origin, ascent, and eruption of the lunar A17 orange glass magma has been constructed using petrological constraints from gas solubility experiments and from analyses of the lunar sample 74220 to better determine the nature and origin of this unique explosive eruption. Three stages of the eruption have been identified. Stage 1 of the eruption model extends from $\sim 550 \mathrm{~km}$, the A17 orange glass magma source region based on phase equilibria studies, to $50 \mathrm{~km}$ depth in the Moon. Stage 2 extends from $\sim 50 \mathrm{~km}$ to $500 \mathrm{~m}$, where a C-O-H$\mathrm{S}$ gas phase formed and grew in volume based on melt inclusion analyses and measurements. The volume of the gas phase at $500 \mathrm{~m}$ depth below the surface is calculated to be 7 to $15 \mathrm{vol} \%$ of the magma (closed-system) using the minimum and maximum estimates of $\mathrm{CO}, \mathrm{H} 2 \mathrm{O}$, and $\mathrm{S}$ loss from the melt. In Stage 3, depths shallower than $\sim 450 \mathrm{~m}$, the rising magma exsolved an additional 800-900 ppm $\mathrm{H} 2 \mathrm{O}$ and 300 ppm S, increasing the moles in the gas by a factor of 3 to 4 . The closed-system gas phase is calculated to reach $\sim 70 \mathrm{vol} \%$ at $\sim 130 \mathrm{~m}$ depth, enough to fragment the magma and form pyroclastic beads. However, fragmentation (bead formation) is interpreted to have occurred at depths ranging from 600 to $300 \mathrm{~m}$ below the lunar surface based on the pressure necessary to explain the $\mathrm{C}$ content of the orange glass beads. The gas volume (70\%) required to fragment the ascending magma at this depth is a factor of $\sim 5$ greater than the volume determined for closed-system degassing of an orange glass magma at $500 \mathrm{~m}$, strongly implying that the gas was produced by open-system degassing as the magma ascended from greater depths.
\end{abstract}

Formation of the dike carrying the magma up from the $\sim 550 \mathrm{~km}$ deep source is considered to occur by a crack propagation mechanism (Wilson and Head 2003, 2017). The rapid dikepropagation process facilitates gas collection by open-system degassing in the upper part of the dike. This is necessary to achieve the gas volumes required for magma fragmentation at $600 \mathrm{~m}$ 
depths, and the magma-ascent velocities to explain the wide areal distribution of the bead deposit. The explosive nature of the picritic orange glass eruption, and the homogeneity of the bead compositions, are consistent with this gas-assisted eruption scenario, as is the evidence of a Fe-metal forming reduction event during Stage 2 followed by a Stage 3 oxidation event in the ascending magma.

\section{Introduction}

Primitive composition (picritic) glasses were erupted on the Moon as the product of volcanic fire-fountain eruptions (Heiken et al. 1974) that occurred during the main period of mare basalt volcanism (3.3-3.7 Ga; Hiesinger et al. 2011). The picritic glass magmas, which range in composition from low-Ti $(<2 \mathrm{wt} \% \mathrm{TiO} 2)$ green glass to intermediate-Ti $(3-7 \mathrm{wt} \% \mathrm{TiO} 2)$ yellow glass to high-Ti orange, red, and black glasses ( $8-16 \mathrm{wt} \% \mathrm{TiO} 2)$, erupted primarily as phenocryst-free melts (Delano 1986). At the time of eruption, only the Apollo 17 orange glass beads contained phenocrysts, $<1 \mathrm{vol} \%$ of Fo 81 olivine in the form of $<800 \mathrm{~mm}$ crystals (Heiken et al. 1974; McKay et al. 1978; Weitz et al. 1999). Picritic glass occurrences are widespread on the lunar near side, with glasses identified at all of the Apollo lunar landing sites (Delano 1986). Many of the deposits are correlated with Dark Mantle deposits on the lunar surface (Head 1976; Gaddis et al. 1985; Weitz et al. 1998); almost all are in mare-filled basins or on their margin (Gaddis et al. 2003).

The origin of the picritic lunar glass magmas is generally accepted as being due to partial melting of different zones in the upper lunar mantle that were formed by crystallization and cumulate overturn in a Lunar Magma Ocean (Delano 1986; Hess and Parmentier 1995; Shearer et al. 2006). Assuming that the major phases left in the source region were olivine and low-Ca pyroxene, experimental studies indicate that the picritic magmas formed at depths of 300-500 $\mathrm{km}$ in the Moon by relatively low degrees of partial melting (Green et al. 1975; Walker et al. 1975; Delano 1980; Krawczynski and Grove 2012; Brown and Grove 2015). The cumulate overturn best explains the relatively high $\mathrm{Mg} \#$ of the picritic magmas and the ilmentite accumulation that is required in the high-Ti magma source regions ( $\sim 500 \mathrm{~km}$ depths) to produce partial melts with $8-16 \mathrm{wt} \% \mathrm{TiO} 2$. Without overturn, crystal fractionation of the lunar magma ocean would have produced a relatively evolved (low $\mathrm{Mg} / \mathrm{Fe}$ ) olivine+pyroxene upper mantle, and ilmenite would only have appeared in the final stages of LMO crystallization just below the plagioclase-rich crust (Snyder et al. 1992; Elkins-Tanton et al. 2011). The cumulate overturn also helps to explain the partial melting in the upper mantle because melting is enhanced by mixing of hot, low-density Mg-rich cumulates from depth and ilmentite-rich 
cumulate from above. Several significant questions remain, however; and here we attempt to address three of them. (1) Now that we know there were volatiles dissolved in lunar picritic magmas as they ascended from depth in the Moon (Saal et al. 2008; Hauri et al. 2011; Chen et al. 2015; Wetzel et al. 2015; McCubbin et al. 2015), can we determine the composition and volume of the gas phase as a function of depth? (2) What role, if any, did these volatiles play in causing the relatively dense (Fe-rich) picritic magmas to ascend through the thick plagioclase-rich lunar crust (Krawczynski and Grove 2012; Xu et al. 2014) without significant cooling and crystallization? (3) Was the abundance and composition of the exsolved volatiles sufficient to explain the small bead diameter and petrological characteristics of glass particles in the various eruption (Heiken and McKay 1977; Housley 1978; Delano 1986; Longhi 1992) deposits? The approach used to gain answers to these questions was to evaluate the potential importance of the volatiles determined to be present in the A17 orange picritic glass magma (OPGM) at various points in its ascent and eruption. We focus on the A17 OPGM because there are more analytical data available for this magma composition than others, but the model should also apply to picritic green and yellow glass magmas, since they erupted with the same explosive style (Delano 1986) and at essentially the same low oxidation state (Fogel and Rutherford 1995).

\section{Gas phase formation in ascending picritic magmas}

\section{Data on C-O-H abundance in picritic melts}

Data on the abundance of $\mathrm{C}$ and $\mathrm{H} 2 \mathrm{O}$ in the OGPM based on bead and melt inclusion analyses is summarized in Figure 1. Analyses of individual glass beads (lower left in Fig. 1) show that $\mathrm{C}$ and $\mathrm{H} 2 \mathrm{O}$ are present at the parts per million level in the A17 orange and in A15 green and yellow glass beads. The variations in dissolved water at nearly constant $\mathrm{C}$ content are interpreted as indicating kinetically controlled $\mathrm{H} 2 \mathrm{O}$ degassing after the beads were formed (Wetzel et al. 2015). This interpretation is supported by the fact that the core to rim trend in an individual yellow bead (red triangles in Fig. 1) mimics the trend for individual beads as a group, and the fact that the expected rapid diffusion of H vs. C (Fogel and Rutherford 1995; Saal et al. 2008) would produce such a trend in a rapidly cooling pyroclastic bead. Analyses of olivinehosted melt inclusions in the A17 orange glass (Hauri et al. 2011; Wetzel et al. 2015) show that higher amounts of C (up to $4 \mathrm{ppm}$ ) and $\mathrm{H} 2 \mathrm{O}$ (500 to $1200 \mathrm{ppm}$ ) were present when samples of melt were trapped by olivine during its growth at depth in the Moon. These melt inclusions define the ascent path of this magma in equilibrium with a CO-rich vapor phase with $\sim 0.01$ mole fraction $\mathrm{H} 2 \mathrm{O}$ (Wetzel et al. 2015). Melt inclusions in the A17 orange glass olivine contain 
shrinkage bubbles, although it was possible to measure the bubble size for only two inclusions (Wetzel et al. 2015). The total $\mathrm{C}$ and $\mathrm{H}$ present in the two inclusions, illustrated by the red squares in Figure 1, was calculated assuming the CO-rich gas in the shrinkage bubble equilibrated with the melt to the glass transition temperature. This calculation suggests there could have been as much as 44-64 ppm C and 476-752 ppm H2O in the melt when these inclusions were trapped (Wetzel et al. 2015), but this is probably a maximum estimate of the $\mathrm{C}$ present in the OGM as discussed in the following section.

\section{CO solubility as a function of pressure: Depth of $\mathrm{C}$ and $\mathrm{H}$ degassing}

To use the volatile analyses of the natural samples to determine the origin and amount of the gas phase in the lunar picritic magmas as a function of depth, either a solubility model or experimental data are required. Experiments at appropriate conditions have been performed on C-O-H solubility in a picritic A15 green glass composition (Wetzel et al. 2013) and on Fe-rich basalts (Stanley et al. 2014; Armstrong et al. 2015). This work demonstrated that $\mathrm{C}$ is dissolved primarily as CO (Armstrong et al. 2015), and the total dissolved $\mathrm{C}$ decreases with decreasing pressure (Fig. 2) for a fixed carbon activity, and a lunar oxidation state (IW-1). The Wetzel et al. (2013) experiments were done primarily with low dissolved water content (1000 ppm) following indications from the melt inclusion data (Hauri et al. 2011), and all contained an excess gas phase (vesicles). Data for similar experiments on the A17 orange glass compositions (Appendix1) plotted in Figure 2 show the same $\mathrm{C}$ solubility vs. pressure relationship as that of the green glass. The calculated composition of the coexisting C-O-H gas phase using the Zhang and Duan (2009) model for these conditions is shown as a function of pressure in Figure 3. The

high and increasing mole fraction of $\mathrm{CO}$ at pressures below $200 \mathrm{MPa}$ is consistent with the high $\mathrm{CO}$ and relatively low $\mathrm{CH} 4$ and $\mathrm{H} 2$ indicated by FTIR and Raman spectra of the experimental glasses in this pressure range (Wetzel et al. 2013, 2015). We note that while Wetzel et al. $(2013,2015)$ identified the dissolved $\mathrm{C}$ as Fe-carbonyl based mainly on the presence of a peak in the Raman spectra, Yoshioka et al. (2015) have now shown convincingly that the dissolved species is almost certainly a variably coordinated CO species. Importantly, the uncertainty in the $\mathrm{C}$ speciation in the melt does not alter the solubility data (Fig. 2) used here, since they are based on SIMS analyses of C.

To obtain the $\mathrm{C}(\mathrm{CO})$ concentration in the ascending OPGM, we use the orange glass solubility curve in Figure 2, because it was determined over the pressure range that we are attempting to investigate (300 to $0 \mathrm{MPa}$ ). Recent 1.2 GPa experiments (Armstrong et al. 2015) on the solubility of $\mathrm{C}$ in basaltic melts with similar small amounts of dissolved water 
demonstrated a correlation of dissolved $\mathrm{CO}$ abundance with $f \mathrm{CO}$ as well as pressure. These data have not been used here because they were primarily at one pressure, and most experiments were at $f \mathrm{O}_{2}$ values above and below the lunar (IW-1.0) value, where oxidized $\mathrm{C}$ (carbonate) and $\mathrm{FeO}$ reduction, respectively, became important.

The pressure isobars in Figure 4 indicate that the $\mathrm{C}$ measured in the melt inclusion glasses was quenched in at pressures from 17 to $2 \mathrm{MPa}$ or from about 4 to $0.5 \mathrm{~km}$ depth in the lunar crust. This pressure estimate is a minimum, however, because it assumes an activity of $\mathrm{C}=1$ in the magma, and this was probably not the case as discussed below. Additionally, when the $\mathrm{CO}$ contents of the gas bubbles in the melt inclusions are added back into the inclusion glass, the estimate of pressure (depth) of inclusion entrapment moves to higher values. The degassing recorded by the melt inclusions possibly began at a depth of $52 \pm 9 \mathrm{~km}$ (Wetzel et al. 2015) where a graphite-saturated magma would have contained as much as $50 \pm 6 \mathrm{ppm} \mathrm{C} \mathrm{(117} \mathrm{ppm}$ CO) and $\sim 1000$ ppm H2O as indicated by bubble-bearing melt inclusions (Fig. 1). However, because it is possible that the shrinkage bubbles were not filled with the CO-rich gas at the glass transition temperature (Steele- Macinnis et al. 2011; Hartley et al. 2014; Moore et al. 2015), we conclude that this is a maximum CO content for the OPGM during M.I. entrapment, and $52 \mathrm{~km}$ is a maximum depth estimate.

We refer to degassing of the OGPM from 52 to $0.5 \mathrm{~km}$ depths as Stage 2, and any degassing that might have occurred at greater than $52 \mathrm{~km}$ depth as Stage 1. Stage 2 degassing ended at a pressure of $\sim 2 \mathrm{MPa}$, approximately $0.5 \mathrm{~km}$ below the lunar surface, where the melt began losing significant $\mathrm{H} 2 \mathrm{O}$ with very little loss of $\mathrm{CO}$ (Fig. 4). The dissolved $\mathrm{H} 2 \mathrm{O}$ remaining in the orange glass beads after they were quenched ranges from 1-10 ppm, while the $\mathrm{C}$ ranges from 0.35 to $0.65 \mathrm{ppm}$ (Fig. 1). Melt inclusions with the same low $\mathrm{C}$ content as the beads $(0.45$ ppm) contain 400 and 830 ppm dissolved H2O (Fig. 4). We interpret the inclusion with 830 ppm $\mathrm{H} 2 \mathrm{O}$ and $0.45 \mathrm{ppm} \mathrm{C}$ as representative of the low-pressure end of the equilibrium degassing trend that began at depths $>4 \mathrm{~km}$ in the crust, and suggest that the four other inclusions with $<1$ ppm $\mathrm{C}$ and 400-600 ppm H2O lost water $(\mathrm{H})$ by diffusion through the host olivine during the initial part of Stage 3 (e.g., Cottrell et al. 2002; Le Voyer et al. 2014), or that some of this H-loss occurred as these melts transitioned from embayments to sealed off inclusions in the host olivine. $\mathrm{Cl}$ in the same four inclusions is also anomalously low (next section). It follows that approximately $900 \mathrm{ppm} \mathrm{H} 2 \mathrm{O}$ was added to the gas phase during this final stage (Stage 3 ) of the eruption, i.e., as the magma went from $\sim 500 \mathrm{~m}$ below the lunar 
surface to where the beads cooled to temperatures below the glass transition in the volcanic eruption cloud.

The transition from Stage 2 to Stage 3 of the OPGM ascent occurred at depths ranging from 300 to $600 \mathrm{~m}$ for different batches of magma. The depth range comes from the pressures indicated by the $\mathrm{C}$ content of the individual orange glass beads (Fig. 1; Wetzel et al. 2015). We reason that while the core compositions of beads have experienced little or no $\mathrm{C}$ loss after magma fragmentation, as indicated by the single bead profile (Fig. 1), C gains would not be possible. Therefore, the C-pressures for the beads give a minimum pressure estimate for bead formation at the beginning of Stage 3. Wetzel et al. (2015) concluded that the Stage 2-3 transition represents a change from equilibrium degassing to kinetically controlled degassing accompanied by melt fragmentation; to confirm this conclusion, we need to assess the volume and degassing behavior of all gas phase components present in the OPGM.

\section{Partitioning of $\mathrm{S}, \mathrm{F}$, and $\mathrm{Cl}$ into the volcanic gas phase}

There have been several experimental and analytical studies of S, F, and $\mathrm{Cl}$ partitioning into the volcanic gas phase in terrestrial basaltic magmas where the $\mathrm{C}$ is dissolved primarily as carbonate (e.g., Moune et al. 2009; Lesne et al. 2011) and the water contents are relatively high, but there has been little research on the behavior of these elements at lunar oxidation states. Ustunisik et al. (2015)'s experiments on degassing were done with nominally C-free glasses containing $2.3 \mathrm{wt} \%$ dissolved $\mathrm{H} 2 \mathrm{O}$, and thus are not useful for evaluating the early degassing of a CO-bearing OPGM with 1000 ppm H2O. Thermodynamic calculations (Sato 1976; Fogel 1989) indicate that CO and CO2 are the only species in the C-O-S system for which the fugacity is greater than $1 \mathrm{MPa}$ at $200 \mathrm{MPa}$ and $1400{ }^{\circ} \mathrm{C}$. This suggests that unless the $\mathrm{H}$ component causes $\mathrm{S}$ to enter the gas phase, possibly as H2S, S would not be a large component of the OPGM gas phase at lunar crustal pressures. Similar thermodynmic calculations for the C-OH-S system (Gaillard and Scaillet 2009) indicate that S species (SO2, H2S, and S2) become minor components of the gas phase, but only at pressures $<1 \mathrm{MPa}$ at lunar oxidation states (COS was not included in this calculation). Given this limited experimental and theoretical data for $\mathrm{S}, \mathrm{Cl}$, and $\mathrm{F}$ partitioning behavior between melt and $\mathrm{CO}$-rich gas phases at lunar oxidation states, we turn to the constraints that come from analyses of the olivine-hosted melt inclusions in the natural A17 OPGM sample.

The behavior of $\mathrm{S}, \mathrm{Cl}$, and $\mathrm{F}$ in the OPGM as it degassed during ascent through the lunar crust is shown by the melt inclusion and bead analyses (Fig. 5). The four inclusions with low dissolved $\mathrm{H} 2 \mathrm{O}$ and relatively low $\mathrm{C}$ that were interpreted as affected by post Stage 2 diffusive water loss also have low $\mathrm{Cl}(1.1-1.5 \mathrm{ppm})$ relative to the inclusion with $0.45 \mathrm{ppm} \mathrm{C}$ and 803 
ppm $\mathrm{H} 2 \mathrm{O}(2.1 \mathrm{ppm} \mathrm{Cl})$. Assuming the $\mathrm{Cl}$ in these four anomalous inclusions was also affected by selective post- Stage 2 diffusion, possibly just before the inclusion was sealed off in the host crystal, the remaining melt inclusion data show no measurable partitioning of $\mathrm{Cl}$ into the Stage 2 gas phase. In contrast, the $\mathrm{Cl}$ loss during Stage $3(1.5 \mathrm{ppm})$ was a large percentage of original $\mathrm{Cl}$ in the inclusions even though it did not contribute significantly to the total moles of gas produced. Sulfur, however, was clearly a significant component of the gas produced during the OPGM eruption. A line through the M.I. data suggests that there was possibly $50 \mathrm{ppm}$ of Sloss to the gas phase during the Stage 2 ascent of the OPGM. This suggestion holds even though the lowest $\mathrm{S}$ data point (447 ppm) is for the inclusion with the second lowest $\mathrm{H} 2 \mathrm{O}$ (510 ppm) and lowest $\mathrm{Cl}$ (1.2 ppm) contents, and may not represent Stage 2 degassing of S. We tentatively conclude that as much as $50 \mathrm{ppm} \mathrm{S}$ was probably added to the gas phase in Stage 2, and 300 ppm S (plus 1 ppm $\mathrm{Cl}$ ) was added to the gas phase during Stage 3.

The melt inclusion data for $\mathrm{F}$ (Fig. 5c) suggest that there was an average of $\sim 50 \mathrm{ppm} F$ in the OPGM melt as the CO-rich gas phase formed during Stage 2 of the eruption. The inclusion with an anomalously low F content (at $1 \mathrm{ppm} \mathrm{C}$ ) is an inclusion interpreted to have lost $\mathrm{H} 2 \mathrm{O}$ to the gas phase just before or after the entrapment. Given that the remaining inclusions contain an average of $52 \mathrm{ppm} \mathrm{F}$, and the beads contain an average of $13 \mathrm{ppm}$, we conclude that the OPGM lost $\sim 40$ ppm F to the gas phase in Stage 3 of the eruption.

\section{Gas volumes in OPGM as function of depth}

We conclude that the OPGM magma first became saturated with a CO-rich gas at a depth between 4 and $52 \mathrm{~km}$; to calculate the end-member case, we also initially assume that the bubbles stayed in the melt volume where they formed (closed-system). The gas formed during the Stage 2 ascent from 52 to $0.5 \mathrm{~km}$ depth (Table 1) included a minimum of 12 and maximum of $115 \mathrm{ppm} \mathrm{CO}(\mathrm{wt})$ and possibly as much $50 \mathrm{ppm} \mathrm{S}$. At $0.5 \mathrm{~km}$ depth, the volume of the CO would have reached a maximum of $7.7 \mathrm{vol} \%$, or it could have been as low as $1 \mathrm{vol} \%$ (12 ppm $\mathrm{CO}$ ). We assume (Table 1) that the $50 \mathrm{ppm} \mathrm{S}$ might have occurred equally as SO2, S2, and $\mathrm{H} 2 \mathrm{~S}$ in the gas phase following thermodynamic calculations (Gaillard and Scaillet 2009). The $\mathrm{CO}$ and $\mathrm{S}$ yield a minimum of 0.8 and a maximum total of $4.1 \mathrm{~mL}$ of gas in $33 \mathrm{~mL}$ of melt, equivalent to 2.4 to $9 \mathrm{vol} \%$ of the magma at $0.5 \mathrm{~km}$ depth.

In Stage 3 of the magma ascent, 900 ppm dissolved H2O moved into the gas phase along with an additional 300 ppm S, probably by kinetically controlled degassing after bead formation. The above-mentioned calculations of gas-phase composition indicate that this $\mathrm{S}$ occurs approximately equally as $\mathrm{SO} 2, \mathrm{~S} 2$, and $\mathrm{H} 2 \mathrm{~S}$, but $\mathrm{H} 2$ is already in the gas, and the reaction with 
$\mathrm{S}$ to form H2S does not produce additional gas moles. Similarly, the $40 \mathrm{ppm}$ F and 1-1.5 ppm $\mathrm{Cl}$ transferred to the gas phase in this stage are also assumed to have added no additional moles to the gas phase since they would have occurred as HF and $\mathrm{HCl}$ (Symonds et al. 1988; Ustunisik et al. 2015). The Stage 3 gas release $(0.005 \mathrm{~mol} \mathrm{H} 2 \mathrm{O}$ and $0.0005 \mathrm{~mol} \mathrm{~S} 2+\mathrm{SO} 2)$ would account for at least $92 \%$ of the moles of gas present at $24 \mathrm{~m}$ below the lunar surface ( $1 \mathrm{~atm}$ ), and in this closed-system ascent the magma would be 96 vol\% gas. However, some fraction of the Stage 3 gas was clearly lost from melt beads after they exited the lunar surface (Saal et al. 2008). Although the Saal et al. (2008) estimate is based on diffusion profiles in the A15 green glass beads, we use this as a guide to post-eruption processes in OPGM beads. We estimate that onehalf to two-thirds of the $900 \mathrm{ppm}$ water was lost by diffusion from the beads during their ballistic flight after leaving the vent by comparing the $300 \mathrm{~s}$ flight time (Saal et al. 2008) with an estimate of the $50-100 \mathrm{~s}$ time for ascent from $500 \mathrm{~m}$ to the surface $(500 \mathrm{~m}$ at $\sim 5-10 \mathrm{~m} / \mathrm{s}$; Rutherford and Papale 2009). This change lowers the closed-system gas volume to 94 and 93 vol\%, respectively, when the magma is $25 \mathrm{~m}$ below the lunar surface.

Two additional factors could have been involved in the above gas volume assessment; both could significantly increase the amount of gas present in a given volume of magma during its ascent through the lunar crust. First, it is possible that there was enough dissolved CO in the ascending magma to cause gas saturation deeper than is indicated by the melt inclusions. If the melt became CO-saturated at the base of the lunar lithosphere, $\sim 100 \mathrm{~km}$ depth at $3.7 \mathrm{Ga}$ (Weiczorek et al. 2010), the total CO eventually released to the gas would have increased by a factor of 2 . The gas volume at $0.5 \mathrm{~km}$ depth would have been 18 rather than 9 vol\% of the magma, and the gas would have been CO-rich, but the Stage 3 degassing of $\mathrm{H} 2 \mathrm{O}$ (and S) would still be $\sim 85 \mathrm{vol} \%$ of the gas phase in the magma at $25 \mathrm{~m}$. The other major factor that could have increased the gas volumes in the ascending magma at any depth is gas separation from the melt (open-system degassing). As discussed in the following section, gas separation is considered a key part of the dike propagation process that established the conduit.

\section{Model of picritic glass magma eruption}

Original models for the formation of the lunar picritic glass deposits were generally based on an analogy with volcanic fire-fountaining such as is commonly observed in Hawai'i (Heiken et al. 1974; Housley 1978; Rutherford and Papale 2009). These models considered a steadystate magma flow in an established conduit. However, the characteristics of the lunar glass bead deposits (e.g., Weitz et al. 1998) require that we also consider the original feeder dike formation (Wilson and Head 2003). The OPGM is considered to have originated at $\sim 550 \mathrm{~km}$ 
depth in the Moon's upper mantle. This depth estimate is based on experiments showing that a mantle containing olivine, low-Ca pyroxene, Ca-pyroxene, and ilmenite (plus other minor phases) would have retained the two major phases (olivine and low-Ca pyroxene) only after partial melting at $\sim 1550{ }^{\circ} \mathrm{C}$ (Krawcyznski and Grove 2012). The partial melt formed under these conditions would have been slightly less dense than the surrounding residual mantle, tending to rise along grain boundaries, and collecting in small melt pools within a rising diapir (e.g., Longhi 1992). Magma separation at $550 \mathrm{~km}$ is geochemically required since there is no evidence of melt re-equilibration or reaction with the residual mantle at depths above $550 \mathrm{~km}$. Wilson and Head $(2003,2017)$ suggest that a dike would begin to propagate upward from the melt-rich zone when the melt in this zone became interconnected (i.e., a few percents of partial melting), causing the pressure on the overlying rocks to increase with the size of the connected melt zone. The excess pressure generated would vary depending on the vertical extent of the melt zone, the density difference between the melt and host rocks, and the local acceleration due to gravity. Wilson and Head (2017, their Table 2) calculate that a $25 \mathrm{~km}$ vertical melt-rich column would be sufficient to initiate a dike that would rise $78.5 \mathrm{~km}$ from a melt zone at 500 $\mathrm{km}$ depth, and the dike width would reach $112 \mathrm{~m}$. The model indicates that the dike would separate from the source at this point (top of dike at $\sim 450 \mathrm{~km}$ depth) due to the increasing riserate of the dike tip and the inability of the melt source region to maintain melt-supply and overpressure at the base of the dike (Fig. 6). According to the model, the disconnected dike would rise rapidly $(\sim 30 \mathrm{~m} / \mathrm{s})$ through the overlying mantle and crust due to its buoyancy. In the dike propagation process, a transient low-pressure is produced at the crack tip as each new fracture occurs because the melt cannot move into the new crack at the crack-forming rate. We know that a stable gas phase may have formed in the ascending OPGM at $\sim 52 \mathrm{~km}$ depth based on the vapor bubbles in melt inclusions described above, but this model predicts it may have formed locally at greater depths due to the low-pressure in the dike tip. Once a gas phase formed near the dike tip, the crack formation mechanism would tend to cause further gas-melt separation near the top of the dike. As the tip reaches the surface, the bubble-rich magma might extend for several kilometers behind the tip according to the model (Fig. 6 inset). Given the rapid increase in gas volume in the magma over the final $0.5 \mathrm{~km}$, we expect the exit velocity at the vent quickly reached the maximum sonic limit for choked flow (Wilson and Head 2003, 2017).

\section{Unique eruption characteristics explained by the model}




\section{Ascent and eruption}

The above model for the orange glass magma dike-initiation, propagation, and approach to the surface explains many of the unique aspects of the deposit formed near the Apollo 17 site. The fine grain size of the glass beads $(<1 \mathrm{~mm})$ and the widespread area $(3000 \mathrm{~km} 2$; Gaddis et al. 2003) covered by the deposit require that the magma must have been very gas-rich and ascending rapidly as it reached the surface (Housley 1978; Wilson and Head 2017). The sample data and calculations indicate that the magma contained at least $8-15 \mathrm{vol} \%$ gas bubbles at 0.5 $\mathrm{km}$ depth in the crust and at least $93-94$ vol\% at $25 \mathrm{~m}$ depth based on closed-system degassing of the $\mathrm{CO}, \mathrm{S}, \mathrm{F}, \mathrm{Cl}$, and $\mathrm{H} 2 \mathrm{O}$ present in the melt at these depths. This gas volume is not sufficient to cause magma fragmentation (Papale 1999; Gonnermann and Manga 2013) at the Stage 2-3 transition ( $\sim 500 \mathrm{~m}$ depth) of an OPGM with the initial C contents considered (4-50 ppm). Using the same MI data, and their O-H speciation and solubility data, Newcombe et al. (2017) reach the same conclusion. They determine that the O-H gas phase alone would have caused fragmentation at a pressure of $\sim 5$ bars for batch (closed-system) degassing C-O-H species in the OPGM. The contribution of $\mathrm{SO} 2+\mathrm{S} 2$ to the Stage 3 gas increases the moles of gas present by only 5\%. Based on these observations, fragmentation of the OPGM magma would have occurred at a minimum pressure slightly greater than 5 bars $(125 \mathrm{~m})$ assuming closed-system degassing. However, as argued above, bead formation almost certainly occurred as deep as 300-600 m. This depth range corresponds to the pressure needed to explain the $\mathrm{C}$ that remains in the cores of individual beads (Fig. 1; Wetzel et al. 2015). Also supporting this conclusion is the fact that the Stage 3 degassing profiles in individual beads can be best modeled by bead diffusion processes (Saal et al. 2008; Wetzel et al. 2015) beginning in this depth range. The amount of gas required ( $70 \mathrm{vol} \%$ ) to cause fragmentation at $\sim 500 \mathrm{~m}$ is a factor of 5-10 greater than that produced by the closed-system ascent described above; we suggest the excess gas was probably caused by open-system degassing during the earlier OPGM ascent.

The fact that no extrusive lava flow samples of picritic magma composition have been observed in Apollo sample collections (e.g., Sonzogni and Treiman 2014) may be explained in part by the collection of volcanic gas near the dike tip during the eruption of these magmas. Immediately after the dike reached the surface, downward moving shock waves would lower the pressure of the magma in upper part of the dike until an equilibrium pressure gradient was established in the dike (Wilson and Head 2017), and this would cause some additional degassing, particularly in the upper half of the dike. However, after the initial eruption, magma reaching the surface would have experienced lesser and lesser amounts of open system gas 
concentration because it was further removed from the dike-tip process. The result could be that magma at depth in the dike does not have sufficient gas to maintain the overpressure that keeps the dike open and erupting (Wilson et al. 2014) beyond the initial stages. A continuation of this process could end the eruption as the dike closes laterally before gas-poor magma could reach the surface (Wilson and Head 2017). The fact that the dike was likely separated from the mantle source before the eruption began (Fig. 6), could also have played a role in preventing OPGM flows from reaching the lunar surface given that once the eruption began, further upward movement of the dike would slowly decrease the overall buoyancy of such a dike.

The distance from the vent traveled by the glass beads formed in the OPGM eruption is a function of the velocity of the gas bead mixture at the vent, the expansion of the gas phase present at the vent, and the energy still to be released as additional gas is lost from the melt beads and expands into the lunar vacuum (Wilson and Head 2003, 2017; Wilson et al. 2014). Wilson and Head (2017) use 2000 ppm dissolved CO and 1000 ppm H2O, and find the gas release and expansion is not sufficient to cause exit velocities (300-400 km/s) necessary to drive the beads as far as might be required ( $>30 \mathrm{~km}$ radius of the A17 dark mantle deposit). However, this problem could be reduced or even removed for the early volumes of magma reaching the surface if sufficient gas was added to these magmas by the open system degassing. The nature of the dike-tip propagation process makes it difficult to quantitatively determine the magma ascent velocity as the first kilometers of magma reaches the surface, but once the vent is open, the flow in the dike would rapidly approach the conduit flow simulated by Rutherford and Papale (2009). According to this calculation a minimum magma velocity estimate would be in the range of 5 to $15 \mathrm{~m} / \mathrm{s}$ at $500 \mathrm{~m}$ depth assuming the $7-15 \mathrm{vol} \%$ gas present at this depth. The velocity of the mixture at the vent could be more than twice this estimate given the addition of large volumes of $\mathrm{H} 2 \mathrm{O}$ and $\mathrm{S}$ species transferred to the gas phase in the first $500 \mathrm{~m}$ of the Stage 3 degassing. Additionally, a large fraction (50-60\%) of the H2O added to the gas in Stage 3 would have been present as H2 (Newcombe et al. 2017), which would decrease the density of the gas phase by a factor of 5 relative to a gas with just $\mathrm{H} 2 \mathrm{O}$. This would significantly increase the velocity of the ascending magma during Stage 3 both below the surface, and in the expanding hot gas cloud carrying the beads away from the vent.

\section{Origin of the Fe-metal grains}

The origin of Fe-rich metal beads observed in the OPGM and other picritic glass deposits (Reid et al. 1970; Brett 1976; Sato 1976; Fogel and Rutherford 1995; Weitz et al. 1997) must be considered in a model explaining these eruptions. Metal beads trapped in olivine 
phenocrysts of the OPGM are homogenous (Fe85Ni14Co1). An origin of the metal by graphite oxidation (Sato 1976; Nicholis and Rutherford 2009) now seems unlikely because the metal grains were trapped by growing olivine phenocrysts that formed at depths of 4-50 km (or greater) based on the $\mathrm{CO}$ content of the olivine-hosted melt inclusions (Fig. 4). If the magma was carrying graphite, it had to be included in the partial melting region, since there is no plausible reaction to cause graphite formation in the ascending magma carrying dissolved $\mathrm{CO}$ as the only $\mathrm{C}$ source. Release of $\mathrm{CO}$ from the rising melt could occur, but reduction of $\mathrm{CO}$ to form graphite would cause oxidation of $\mathrm{FeO}$ in the melt, the reverse of what is observed. Also, graphite in the OPGM in the $550 \mathrm{~km}$ deep source region would require that the melt contain 550 ppm C as dissolved CO according to the solubility data (Wetzel et al. 2013). A comparison of volatile element ratios in the OPGM and depleted terrestrial mantle shows similar ratios of $\mathrm{H} / \mathrm{C}$ (and $\mathrm{S} / \mathrm{Cl}$ and $\mathrm{F} / \mathrm{S}$ ) when the melt has $52 \mathrm{ppm}$ dissolved $\mathrm{C}$ (Wetzel et al. 2015), suggesting that the $550 \mathrm{ppm} \mathrm{C}$ concentration estimate is too high. We conclude that graphite was probably not carried up from depth in the orange glass magma, and the melt was not likely saturated with $\mathrm{CO}$ at $550 \mathrm{~km}$. Additionally, while the breakdown of dissolved Fe-carbonyl would have the potential to produce the Fe-metal (Wetzel et al. 2013), this process no longer appears viable since Yoshioka et al. (2015) have shown that the dissolved species in a mafic melt is almost certainly not Fe-carbonyl.

A process that can explain the Fe-metal formation during (or before) the Stage 2 OPGM ascent is one that involves S loss from the melt (Brett 1976). The loss of up to $50 \mathrm{ppm} \mathrm{S}$ during this stage is suggested by the melt inclusion data (Fig. 5; Table 1). The speciation of the S may have been either as COS (Sato 1976; Fogel and Rutherford 1995) or possibly SO2 (Gaillard and Scaillet 2009) in the gas phase, and as FeS species in the melt (i.e., Danckwerth et al. 1979); either case could produce Fe-rich metal grains in the magma. This suggestion does mean that the $\mathrm{S}$ addition to the gas phase occurred at somewhat higher pressures $(>2 \mathrm{MPa})$ than those indicated by the Gaillard and Scaillet (2009) thermodynamic calculations, and this needs to be investigated further by additional calculations or experiments. A possible reaction would be FeSmelt $+\mathrm{CO}=$ Femetal $+\mathrm{COS}$; another would be FeS $+2 \mathrm{H} 2 \mathrm{O}=$ Femetal $+\mathrm{SO} 2+2 \mathrm{H} 2$. These reactions would be driven by equilbrium partitioning of $\mathrm{S}$ between a C-O-H gas and the picritic melts, and do not require the melts to be saturated with FeS (Danckwerth et al. 1979).

\section{Late-stage oxidation}

The OPGM experienced an oxidation event late in its eruption history as indicated by Nirich rims on all of the Fe-metal grains that were not enclosed in olivine phenocrysts (Weitz et al. 1997). The Ni contents in these beads ranged from $14 \mathrm{wt} \%$ in the core up to $30 \mathrm{wt} \%$ at the 
rim in different size beads, clearly indicating an oxidation event in the magma after the olivine phenocryst growth was completed. This means that the oxidation event took place when the magma had risen above $\sim 500 \mathrm{~m}$ depth in the lunar crust (Fig. 4) during the Stage 3 degassing (Table 1). Weitz et al. (1997) interpreted the oxidation to be caused by the loss of volatile cations such as $\mathrm{K}, \mathrm{Na}, \mathrm{B}$, and $\mathrm{P}$ from the melt to the gas. This explanation is probably correct to some degree, but we also now know that significant amounts of water were lost from the melt during this final explosive ascent stage (Fig. 1; Table 1). Given the $\mathrm{H}$ was dissolved as $\mathrm{OH}$ in the melt (Newcombe et al. 2017) and is calculated to be present primarily as $\mathrm{H} 2 \mathrm{O}$ and H2 in the gas (Gaillard and Scaillet 2009), this gas formation would tend to produce melt oxidation $(4 \mathrm{OH}=\mathrm{H} 2 \mathrm{O}+\mathrm{H} 2+1.5 \mathrm{O} 2)$. Later in Stage 3, diffusive $\mathrm{OH}$ loss might be replaced by selective $\mathrm{H} 2$ diffusion (Saal et al. 2013) contributing further to oxidation of the melt. Identification of relatively high $\mathrm{Fe} 3+/$ Fetotal ratios (ratios of $8-13$ in orange glass) as determined by X-ray adsorption spectroscopy analyses of the orange and other picritic glass beads (McCanta et al. 2017), confirms the presence of a late-stage oxidation in all picritic magmas. The ferric iron content of the OPGM at IW-1.0 would have been less than $1 \mathrm{wt} \%$ of the total Fe present in the melt (McCanta et al. 2009). An observed increase in ferric iron toward the rims of partially crystallized orange glass beads indicates that the oxidation continued while the beads were cooling and developing a microcrystallinity, possibly in the hot gas cloud, but maybe after deposition in the surface deposit as well.

\section{Implications}

The data presented here and previously indicate that degassing in the ascending lunar orange picritic glass magma (OPGM) began with formation of a CO-rich gas at a depth between 4 and $52 \mathrm{~km}$ in the lunar crust. Sulfur and minor water partitioned into this gas phase until the magma reached a pressure of $\sim 2 \mathrm{MPa}$ at a depth of $\sim 500 \mathrm{~m}$. The volume of the gas in the magma at this depth is calculated to be $7-15 \%$, for a closed-system process, sufficient to add to the magma ascent rate, but unable to cause magma fragmentation. Degassing of CO was nearly complete when the magma reached depths of 300-600 m, but strong degassing of the remaining $900 \mathrm{ppm}$ dissolved water and $300 \mathrm{ppm} \mathrm{S}$ began here. On a mole basis, the additional $\mathrm{H} 2 \mathrm{O}$ and $\mathrm{S}$ added during Stage 3 accounted for $80-90 \%$ of the gas in the OPGM as it reached the lunar surface without considering any open-system effects. The closed-system degassing would have caused the OPGM to fragment (70 vol\% gas), and form beads at $\sim 150 \mathrm{~m}$ depth, but the Ccontents of the glass beads require the fragmentation to have occurred in the 300 to $600 \mathrm{~m}$ range. Fragmentation at the latter depths requires a significant (factor of 5-10) increase in the 
gas volume at the start of Stage 3 over that produced by closed-system degassing. The most likely explanation is open-system degassing during Stages 1 and 2, but CO saturation in the $550 \mathrm{~km}$ deep OPGM source region would produce the same result.

The many unique characteristics of the OPGM deposit can be explained using a dike formation model (e.g., Wilson and Head 2003, 2017) that involves a dike forming at the top of a melt-rich zone at $\sim 550 \mathrm{~km}$ depth (Krawczynski and Grove 2012). The rapid rate at which the dike propagates from depth to the surface in this model involves open-system degassing that helps to explain the highly explosive nature of the eruption, the large areal distribution of the deposit, and the fact that the magma was able to pass through the lunar crust without significant cooling or contamination. The formation of Fe-metal beads during Stage 2, and the Stage 3 oxidation of the glass in the ascending magma, are also explained by the degassing.

Previous suggestions for metal formation utilizing either graphite oxidation or the breakdown of Fe-carbonyl dissolved in the melt now appear unworkable, unless the $\mathrm{C} / \mathrm{H}$ ratio in the OPGM magma source was a factor of 10 greater than in Earth's depleted mantle. However, the Fe-metal in the picritic orange glass magma could have formed during the ascent when sulfur, originally coordinated with $\mathrm{Fe}$ in the melt, was transferred into the CO-rich gas phase (Brett 1976) during Stage 2 of the eruption.

\section{Acknowledgements}

The authors acknowledge the constructive suggestions and comments of two anonymous reviewers, and the support of NASA grant NNX16AO83G (M.J.R.). 2052

\section{References}

Armstrong, L., Hirschmann, M.H., Stanley, B.D., Falksen, E.G., and Jacobsen, S.D. (2015) Speciation and solubility of reduced C-O-H-N volatiles in mafic melt: Implications for volcanism, atmospheric evolution, and deep volatiles in the terrestrial planets. Geochimica et Cosmochimica Acta, 171, 283-302.

Brett R., (1976) Reduction of mare basalt by sulfur loss. Geochimica et Cosmochimica Acta, 40, 997-1004.

Brown, S.M., and Grove T.L (2015), The origin of Apollo 14, 15 and 17 yellow ultramafic glass: evidence for late stage overturn of the lunar magma ocean, Geochimica et Cosmochimica Acta, 171, 201-215.

Chen, Y., Zhang, Y.X., Liu, Y., Guan, Y.B., Eiler, J. and Stolper, E.M. (2015) Water, fluorine, and sulfur concentrations in the lunar mantle. Earth and Planetary Science Letters 427, 37-46.

Cottrell, E., Spiegelman, M., and Langmuir, C. H. (2002). Consequences of diffusive reequilibration for the interpretation of melt inclusions. Geochemistry, Geophysics, Geosystems, 3, 1-26. 
Danckwerth, P.A., Hess, P.C., and Rutherford, M.J. (1979) The solubility of sulfur in high$\mathrm{TiO}_{2}$ basalts. Proceedings of the 10th Lunar and Planetary Science Conference, 517530.

Delano, J.W. (1980) Chemistry and Liquidus Phase relations of Apollo 15 red glass: Implications for the deep Lunar Interior. Proceedings of Eleventh Lunar and Planetary Science Conference, 251-288.

Delano, J.W. (1986) Pristine Lunar Glasses: Criteria, Data, and Implications. Proceedings of the Sixteenth lunar and Planetary Science Conference, Part 2. Journal of Geophysical Research, 91, B4, 201-213.

Elkins-Tanton, L.T., Burgess, S., and Yin, Q-Z. (2011) The lunar magma ocean: reconciling the solidification process with lunar petrology and geochronology. Earth and Planetary Science Letters, 304, 326-336.

Fogel, R.A. (1989) The role of $\mathrm{H}-\mathrm{C}-\mathrm{O}-\mathrm{S}$ volatile in planetary igneous processes, $389 \mathrm{p}$. $\mathrm{PhD}$ Thesis, Brown University, Providence, RI.

Fogel, R.A., and Rutherford M.J. (1995) Magmatic volatiles in primitive lunar glasses: I. FTIR and EPMA analyses of Apollo 15 green and yellow glasses and revision of the volatileassisted fire-fountain theory. Geochimica et Cosmochimica Acta, 59, 201-215.

Gaillard, F., and Scaillet, B. (2009) The sulfur content of volcanic gases on Mars. Earth and Planetary Science Letters, 279, 34-43.

Gaddis, L.R., Pieters, C.M., and Hawke, B.R. (1985) Remote sensing of lunar pyroclastic mantling deposits. Icarus, 61, 461-489.

Gaddis, L., Staid, M.I., Tyburczy, J.A., Hawke, B.R., and Petro, N.E. (2003) Compositional analyses of lunar pyroclastic deposits. Icarus, 161, 262-280.

Gonnermann, M., and Manga, M. (2013) dynamics of magma ascent in the volcanic Conduit. Modelin volcanic Processes: The physics and mathematics of Volcanism, eds. Fagents, S.A., Gregg, T.K.P and Lopes, R.M.C., Cambridge University Press, 55-84.

Green, D.H., Ringwood, A.E., Hibberson, W.O., and Ware, N.G. (1975) Experimental Petrology of the Apollo 17 mare basalts. Proceedings of the 6th Lunar and Planetary Science Conference, 871-893.

Hartley M.E., Maclennan J., Edmonds M. and Thordarson T. (2014) Reconstructing the deep $\mathrm{CO}_{2}$ degassing behavior of large basaltic fissure eruptions. Earth and Planetary Science Letters, 393, 120-131.

Hauri, E.H., Weinreich, T, Saal, A.E., Rutherford, M.J., and Van Orman, J.A. (2011) High preeruptive volatile contents preserved in lunar melt inclusions. Science, 333, 213-215.

Hauri, E.H., Saal, A.E., Rutherford, M.J. and Van Orman, J.A. (2015) Water in the Moon's Interior: Truth and consequences. Earth and Planetary Science Letters, 409, 252-264.

Head, J.W., (1976) Lunar volcanism in space and time. Reviews of Geophysics \& Space Physics, 14, 265-300.

Heiken, G.H., McKay, D.S., and Brown, R.W. (1974) Lunar deposits of possible pyroclastic origin. Geochimica et Cosmochimica Acta, 38, 1703-1718.

Heiken, G.H., and McKay D.S. (1977) A model for eruption behavior of a volcanic vent in eastern Mare Serentatis. Proceedings of 8th Lunar Science Conference, 3243-3255.

Hess, P.C., and Parmentier, E.M. (1995) A model for the thermal and chemical evolution of the Moon's interior: Implications for the onset of mare volcanism. Earth and Planetary Science Letters, 134, 501-514.

Hiesinger, H., Head J.W., Wolf, U., Jaumann, R.M., and Neukum, G. (2011) Ages and stratigraphy of lunar mare basalts: A synthesis. Geological Society of America Special Paper, 477, 1-51.

Housley R.M., (1978) Modeling lunar volcanic eruptions: Proceeding of 9th Lunar and Planetary Science Conference, 1473-1484. 
Krawczynski, M.J, and Grove, T., (2012) Experimental investigation of the influence of oxygen fugacity on source depths for high-Ti lunar ultramafic melts. Geochimica et Cosmochimica Acta, 79, 1-19.

Lesne, P., Kohn, S.C., Blundy, J., Witham, F., Botcharnikov, R.E., and Behrens, H. (2011) Experimental simulation of closed-system degassing in the Basalt- $\mathrm{H}_{2} \mathrm{O}-\mathrm{CO}_{2}-\mathrm{S}-\mathrm{Cl}$. Journal of Petrology, 52, 1737-1762.

Le Voyer, M., Asimow, P.D., Mosenfelder, J.L., Guan, Y., Wallace, P.J., Schiano, P., Stolper, E.M., and Eiler, J.M., (2014) Zonation of $\mathrm{H}_{2} \mathrm{O}$ and $\mathrm{F}$ concentrations around melt inclusions in olivines. Journal of Petrology, 55, 685-707.

Longhi, J. (1992) Lunar petrology and petrogenesis of mare volcanics. Geochimica et Cosmochimica Acta 56, p. 2235-2251.

McCanta, M.C., Elkins-Tanton L., and Rutherford M.J. (2009) Expanding the application of the Eu-oxybarometer to the lherzolitic Shergottites and Nakhlites: Implications for the oxidation state heterogeneity of the Martian interior. Meteoritics and Planetary Science, 44, 725-745.

McCanta, M.C., Dyar, D.M., Rutherford, M.J., Lanzirotti, A. Sutton, S.R. and Thomson, B.J. (2017) In Situ measurement of ferric Iron in lunar glass beads using Fe-XAS. Icarus, 285, 95-102.

McCubbin, F.M., Vander Kaaden, K.E., Tartese, R., Klima, R.L., Liu, Y., Mortimer, J., Barnes, J.J., Shearer, C.K., Treiman, A.H., Lawerence, D.J., Elardo, S.M., and others. (2015) Magmatic volatiles (H.C, N, F, S, Cl) in the lunar mantle, crust and regolith: Abundances, distributions, processes, and reservoirs. American Mineralogist, 100, 1668-1707.

McKay, D.S., Heiken, G.H., and Waits, G. (1978) Core 74001/2: Grain size and petrology as a key to the rate of in-situ reworking and lateral transport on the lunar surface. Proceedings of the 9th Lunar and Planetary Science Conference, 1913-1932.

Moore L.R., Gazel E., Tuohy R., Lloyd A.S., Esposito R., Steele-MacInnis M., Hauri E.H., Wallace P.J., Plank T. and Bodnar R.J. (2015) Bubbles matter: An assessment of the contribution of vapor bubbles to melt inclusion volatile budgets. American Mineralogist, 100, 806-823.

Moune, S., Holtz, F., And Botcharnikov, R.E. (2009) Sulfur solubility in andesitic to basaltic melts: Implications for Hekla Volcano. Contributions to Mineralogy and Petrology, 157, 691-707.

Mysen, B.O., Fogel, M.L., Morrill, P.L., and Cody, G. D. (2009) Solution behavior of reduced $\mathrm{C}-\mathrm{O}-\mathrm{H}$ volatiles in silicate melts at high pressure and temperature. Geochemica et Cosmochimica Acta, 73, 1696-1710.

Nicholis, M.G. and Rutherford, M.J. (2009) Graphite Oxidation in the Apollo 17 Orange Glass Magma: Implications for the generation of a lunar volcanic gas phase. Geochimica et Cosmochimica Acta, 73, 5905-5917.

Newcombe, M., Brett, A., Beckett, J.R., Baker, M.B., Newman, S., Guan, Y., Eiler, J.M., and Stolper, E.M., (2017) Solubility of water in lunar basalt at low $\mathrm{P}_{\mathrm{H} 2 \mathrm{O}}$. Geochimica et Cosmochimica Acta, 200, 330-352.

Papale, P. (1999) Strain-induced magma fragmentation in explosive eruptions. Nature, 397, 425-428.

Reid, A.M., Meyer, C., Harmon, R.S., and Brett, R. (1970) Metal grains in Apollo 12 igneous rocks, Earth and Planetary Science Letters, 9, 1-5.

Rutherford, M.J. and Papale, P. (2009). Origin of basalt fire-fountain eruptions on the Earth vs: the Moon: Geology, 37, 219-222. 
Saal, A.E., Hauri, E.H., Lo Cassio, M, Van Orman, J.A., Rutherford, M.J., and Cooper, R.F., (2008) The volatile content of the lunar volcanic glasses: evidence for the presence of water in the Moon's interior, Nature, v. 454, p.192-195.

Saal, A.E., Hauri, E.H., Van Orman, J.A., Rutherford, M.J., (2013) Hydrogen Isotopes in Lunar Volcanic Glasses and Melt Inclusions Reveal a Carbonaceous Chondrite Heritage. Science, 340, 1317-1320.

Sato M. (1976) Oxygen fugacity and other thermochemical parameters of Apollo 17 high-Ti basalts and their implications on the reduction mechanism. Proceeding of 7 th Lunar Planetary Science Conference, 1323-1344.

Shearer, C.K., Hess, P.C., Wieczorek, M.A., Pritchard, M.E., Parmentier, E.M., Borg, L.E., Longhi, J., Elkins-Tanton, L.T., Neal, C.R., Antonenko, I., and others. (2006) Thermal and magmatic evolution of the moon. Reviews in Mineralogy and Geochemistry, 60, 365-518.

Snyder, G.A., Taylor, L.A., and Neal, C.R. (1992) A chemical model for generating the source of Mare basalts: Combined fractional and equilibrium crystallization of the lunar magmasphere. Geochimica Cosmochimica Acta, 56, 3809-3823.

Sonzogni, Y., and Treiman, A.H. (2014) Petrology of a very-low Titanium basalt (or Picrite) Clast in Lunar Highland Regolith Breccia 15295. Lunar and Planetary Science Conference 45, Abstract 1030.

Stanley B. D., Hirschmann M. M. and Withers A. C. (2014) Solubility of C-O-H volatiles in graphite-saturated martian basalts. Geochimica et Cosmochimica Acta, 129, 54-76.

Steele-Macinnis M., Esposito R., and Bodnar R.J. (2011) Thermodynamic model for the effect of postentrapment crystallization on the $\mathrm{H} 2 \mathrm{O}-\mathrm{CO} 2$ systematics of vaporsaturated, silicate melt inclusions. Journal of Petrology 52, 2461-2482.

Symonds, R.B., Rose, W.I., and Reed, M.H. (1988) Contribution of Cl- and F-bearing gases to the atmosphere by volcanoes. Nature, 334, 415-418.

Ustunisik, G., Nekvasil, H., Lindsley, D.H., and McCubbin, F.M. (2015) Degassing pathways of Cl-, F-, H-, and S-bearing magmas near the lunar surface: Implications for the composition and $\mathrm{Cl}$ isotopic values of lunar apatite. American Mineralogist, 100, 1717-1727.

Walker, D., and Longhi, J., and Stolper, E. M. and Grove, T. L., and Hays, J. F. (1975) Origin of titaniferous lunar basalts. Geochimica et Cosmochimica Acta, 39, 12191235.

Weitz C.M., Rutherford M.J., and Head J. W. (1997) Oxidation states and ascent history of the Apollo 17 volcanic beads as inferred from metal-glass equilibria. Geochimica et Cosmochimica Acta, 61, 2765-2775.

Weitz, C.M., Head, J.W., and Pieters, C.M. (1998) Lunar regional dark mantle deposits: Geologic, multispectral and modeling studies. Journal of Geophysical Research, 103, 22,725-22,759.

Weitz C. M., Rutherford M. J., Head J. W., and McKay D. S. (1999) Ascent and eruption of a lunar high-titanium magma as inferred from the petrology of the 74001/2 drill core. Meteorites and Planetary Science, 34, 527-540.

Weiczorek, M.A., Jolliff, B.I., Khan, A., Pritchard, M.E., Weiss, B.P., Williams, J.G., Hood, L.L., Righter, K., Neil, C.R., Shearer, C.K., McCallum, I.S., and others. (2010) The Constitution and Structure of the Lunar Interior, Reviews in Mineralogy and Geochemistry, 60, 2210-364.

Wetzel, D.T., Rutherford, M.J., Jacobsen, S.D., Hauri, E.H., and Saal, A.E. (2013) Degassing of reduced carbon from planetary basalts, Proceedings of the National Academy of Science, 110, 8010-8013. 
Wetzel, D.T., Hauri, E.H., Saal, A.E., Rutherford M.J. (2015) Carbon content of the lunar volcanic glasses and melt inclusions. Nature Geoscience, 8, 755-758.

Wilson, L. and Head, J.W. (2003) Deep generation of magmatic gas on the moon and implication for pyroclastic eruptions. Geophysical Research letters, 30(12), 1605 1609.

Wilson, L., and Head, J.W. (2017) Generation, ascent and eruption of magma on the moon; new insights into source depths, magma supply, intrusions and effusive/explosive eruptions (Part 1: Theory). Icarus, 283, 146-175.

Wilson, L., Head, J.W., and Tye, A.R. (2014) Regional pyroclastic deposits: evidence for eruption from dikes emplaced into the near surface crust. Proceedings of Lunar and Planetary Science Conference 45, Abstract 1223.

$\mathrm{Xu}, \mathrm{Y} ., \mathrm{Zhu}, \mathrm{D}$., and Wang, S. (2014) Constraints on volatile concentrations of pre-eruptive lunar magma. Physics of the Earth and Planetary Interiors, 229, 55-60.

Yoshioka, T., McCammon, C., Shcheka, S., and Keppler, H. (2015) The speciation of carbon monoxide in silicate melts and glasses, American Mineralogist 100, 1641-1644.

Zhang, C and Duan, Z. (2009) A model for C-O-H fluid in the Earth's mantle, Geochimica et Cosmochimica Acta, 73, 2089-2102.

\section{FIGURE CAPTIONS}

Figure 1. Log plot of $\mathrm{C}$ and $\mathrm{H}_{2} \mathrm{O}$ data for glass beads and melt inclusions in $\mathrm{A} 17$ orange and A15 Green and Yellow picritic glass samples. Orange circles are orange glass melt inclusions; orange squares are orange glass beads. A15 green glass beads are green circles, and yellow beads are yellow diamonds. Red diamonds show a core-to-rim profile in a single yellow glass bead. Decreasing $\mathrm{H}_{2} \mathrm{O}$ trend of individual glass bead data is interpreted as diffusion-controlled degassing after bead formation. Melt inclusion data show an apparent equilibrium degassing trend of decreasing $\mathrm{C}$ with little loss of $\mathrm{H}_{2} \mathrm{O}$. Red squares show the composition calculated by adding $\mathrm{CO}$ gas from gas bubbles back into melt inclusions (modified after Wetzel et al. 2015). Figure 2. C solubility for experiments on picritic lunar glass composition melts. Data points for the A17 orange glass (orange circles) and A15 yellow glass (yellow circles) compositions are from the table in the Appendix of this paper; the heavy dark line is a fit to A15 green glass data of Wetzel et al. (2013). The line fit through orange glass data is indistinguishable from the more abundant green glass data; the line fit through the yellow glass experiments shows slightly higher $\mathrm{C}$ contents, but the data set is very small. All data are for a lunar $\mathrm{fO}_{2}$ of IW-1.0 log unit where $\mathrm{CO}$ is the main $\mathrm{C}$ species dissolved in the melt (Wetzel et al. 2015). All melts have low $(<1500 \mathrm{ppm})$ dissolved water, and gas bubbles are present. Activity of $\mathrm{C}=1$ (graphite saturation).

Figure 3. Calculated composition of fluid phase vs. pressure in the $\mathrm{C}-\mathrm{O}-\mathrm{H}$ system for a lunar $\mathrm{fO}_{2}$ of IW $-1 \log$ units, and an activity of carbon $=1$ (graphite saturated) using the Zhang and Duan (2009) program. Note the strong changes in composition of fluid at pressures less than $200 \mathrm{MPa}$. Calculations by Sato (1976), Fogel and Rutherford (1995) and Gaillard and Scaillet (2009) indicate that when $\mathrm{S}$ is added to the system no sulfur species make up more than $1 \mathrm{~mol} \%$ of the vapor phase at $200 \mathrm{MPa}$, but $\mathrm{SO}_{2}, \mathrm{H}_{2} \mathrm{~S}$ and $\mathrm{S}_{2}$ all increase at low $(<1 \mathrm{MPa})$ pressures. Figure 4. Modified C-O-H solubility model of Dixon et al. 1995 (after Wetzel et al. 2015). The solid lines are isobars (crustal depths) and dashed lines are isopleths indicating the fraction of $\mathrm{H}_{2} \mathrm{O}$ in the vapor phase $\left(\mathrm{X}_{\mathrm{H} 2 \mathrm{O}}\right) . \mathrm{H}_{2} \mathrm{O}$ data are from Hauri et al (2015). Orange circles are A17 melt inclusions; other symbols are bead data (See Fig. 1). The pressure contours are not for a fixed activity of C, but Wetzel et al. (2015) found that this model and the experimental solubility curve for graphite saturation (Fig. 2) yielded identical C (ppm) - pressure curves. Figure 5. Plot of $\mathrm{Cl}, \mathrm{S}$ and $\mathrm{F}$ vs. $\mathrm{C}$ in the olivine-hosted melt inclusions (circles) and individual glass beads (squares) for A17 sample 74220. (Data from Saal 2008, Hauri et al. 2011, and 
Hauri et al. 2015). As discussed in the text, $\mathrm{Cl}$ does not appear to partition into the $\mathrm{CO}$-rich gas formed during Stage 2 of the OPGM ascent recorded by the $\mathrm{C}$ decrease in the melt inclusions, but $\sim 50$ ppm S may enter the gas in this Stage. As discussed in the text, four M.I.'s with low $(<1$ ppm C) have very low dissolved $\mathrm{H}_{2} \mathrm{O}$ and low $\mathrm{Cl}$ compared with the highest $\mathrm{H}_{2} \mathrm{O}$ inclusion with equally low $\mathrm{C}$, and are interpreted to have degassed by diffusion through channels prior to sealing by olivine growth. Beginning at $\sim 0.5 \mathrm{~km}$ depth in the crust, $\mathrm{H}_{2} \mathrm{O}, \mathrm{S}, \mathrm{F}$ and $\mathrm{Cl}$ partition strongly into the gas phase as the magma nears the lunar surface and fragments.

Figure 6. Model of lunar OPGM dike emplacement (after Wilson and Head 2017). Circled numbers 1-6 refer to following: (1) Partial melt last equilibrates with residual mantle diapir at $\sim 550 \mathrm{~km}$, and dike propagation begins at contact of melt-rich zone with overlying mantle, (2) dike reaches $\sim 78 \mathrm{~km}$ vertical for a $25 \mathrm{~km}$ (vertical) melt zone, then separates from the source and begins to move very rapidly upward, (3) depth of CO-rich gas formation is $7 \mathrm{~km}$ minimum, $50 \mathrm{~km}$ maximum, followed by continuous degassing of CO-rich gas with ascent; gas and foam collect at dike tip as it propagates, (4) $\sim 7-15 \mathrm{vol} \%$ bubbles in magma at $0.5 \mathrm{~km}$ for closed system degassing, for initial $\mathrm{C}$ contents of 4 to $50 \mathrm{ppm}$, (5) Stage 3 degassing $\left(\mathrm{H}_{2} \mathrm{O}\right.$ and $\mathrm{SO}_{2}, \mathrm{~S}_{2}$ and $\mathrm{H}_{2} \mathrm{~S}$ ) begins with fragmentation (bead formation) at $0.5 \mathrm{~km}$ depth. (6) Dike tip breaches surface releasing melt beads in hot suspension of $>92 \mathrm{vol} \%$ gas. Modified after Wilson and Head (2003).

Appendix 1. A17 Orange and A15 Yellow Picritic Glass Experiments*

\begin{tabular}{|c|c|c|c|c|c|c|c|}
\hline $\begin{array}{c}\text { Sample } \\
\#\end{array}$ & Pressure MP & $\mathrm{T}$ & $\begin{array}{c}\text { C } \\
(\mathrm{ppm})\end{array}$ & $\begin{array}{c}\mathrm{H}_{2} \mathrm{O} \\
(\mathrm{ppm})\end{array}$ & $\begin{array}{c}F \\
(p p m)\end{array}$ & $\begin{array}{c}\mathrm{S} \\
(\mathrm{ppm})\end{array}$ & $\begin{array}{c}\mathrm{Cl} \\
(\mathrm{ppm})\end{array}$ \\
\hline YG-2 & 197 & 1450 & $72(1)$ & $894.4(1)$ & $8(14)$ & $44(1)$ & \\
\hline YG-3 & 195 & 1465 & $63(1)$ & $372.3(1)$ & $8(14)$ & $49(1)$ & \\
\hline YG-4 & 175 & 1465 & $52(2)$ & $599.8(1)$ & $8(10)$ & $41(1)$ & \\
\hline YG-6 & 124 & 1480 & $30(3)$ & $421.9(1)$ & $10(3)$ & $34(2)$ & \\
\hline YG-7 & 126 & 1482 & $37(2)$ & $357.8(1)$ & $8(1)$ & $31(1)$ & \\
\hline YG-11 & 164 & 1465 & $23(5)$ & $249.4(1)$ & $9(1)$ & $33(1)$ & \\
\hline YG-5 & 107 & 1480 & $28(3)$ & $305.4(1)$ & $10(1)$ & $35(1)$ & \\
\hline YG-9 & 132 & 1475 & $32(3)$ & $243.2(1)$ & $8(1)$ & $34(1)$ & \\
\hline SGS-1c2a & 40 & 1360 & $16(7)$ & 191(7) & $4(8)$ & $456(9)$ & $28(9)$ \\
\hline SGS-1e & 80 & 1370 & $36(9)$ & $477(5)$ & $2(5)$ & $1688(3)$ & $19(3)$ \\
\hline SGS-1f & 72.9 & 1370 & $20(5)$ & $175(2)$ & $3(3)$ & $1222(3)$ & $31(5)$ \\
\hline SGS-2 & 42.9 & 1350 & $19(11)$ & $60(2)$ & $3(3)$ & $1381(3)$ & $100(6)$ \\
\hline SGS-1f & 72.9 & 1370 & $17(5)$ & $193.7(1)$ & $2(4)$ & $1273(1)$ & \\
\hline SGS-3 & 50 & 1370 & $13(6)$ & $78.2(1)$ & $2(3)$ & $1113(1)$ & \\
\hline OGV-1 & 105.4 & 1440 & $49(2)$ & $445.3(1)$ & $3037(1)$ & $101(1)$ & \\
\hline OGV-5 & 126 & 1465 & $32(3)$ & $390.5(1)$ & $2145(1)$ & $1260(1)$ & \\
\hline OGV-6 & 146 & 1465 & $14(6)$ & 239.3(1) & $1964(1)$ & $836((1)$ & \\
\hline OGV-7 & 154 & 1465 & $48(2)$ & 384.9 & $2190(1)$ & $1339(1)$ & \\
\hline OGV-8 & 180 & 1465 & $34(3)$ & 291.9 & $2047(1)$ & $1176(2)$ & \\
\hline
\end{tabular}

- Experiments done as described in Wetzel et al. (2013) in graphite-lined Pt tubes with a piece of C-saturated Fe-metal in contact with melt that fixes $\mathrm{fO}_{2}$ at $\sim \mathrm{IW}-1.0$. Run duration was 2 hours in each experiment. Compositions used were the A17 (74220) orange and the A15 (15427) yellow glass as determined by Delano (1986) with 1000 to 2000 ppm of S, Cl, and $\mathrm{H}_{2} \mathrm{O}$. All glasses produced were gas saturated (contained vesicles). Numbers in brackets are 2 sigma analytical errors in the last digit reported for the concentration based on $\sim 10$ analyses (Wetzel et al. 2015). 
Table 1. Summary of gas (ppm wt) formed in A17 OPGM during ascent stages.

\begin{tabular}{|c|c|c|c|c|c|c|}
\hline \multirow[t]{2}{*}{$\begin{array}{c}\text { Gas } \\
\text { Species }^{1} \\
\end{array}$} & \multicolumn{2}{|c|}{$\frac{\text { Stage } 1(\mathrm{ppm})}{(>52 \mathrm{~km})}$} & \multicolumn{2}{|c|}{$\begin{array}{c}\text { Stage } 2(\mathrm{ppm}) \\
(52-0.5 \mathrm{~km})\end{array}$} & \multicolumn{2}{|c|}{$\begin{array}{c}\text { Stage } 3(\mathrm{ppm}) \\
(<0.5 \mathrm{~km}) \\
\end{array}$} \\
\hline & $\underline{\operatorname{Max}}$ & $\underline{\text { Min }}$ & $\underline{\operatorname{Max}}$ & $\underline{\text { Min }}$ & $\underline{\operatorname{Max}}$ & $\underline{\text { Min }}$ \\
\hline $\mathrm{CO}$ & 1280 & 0 & 115 & 12 & 0 & 0 \\
\hline $\mathrm{H}_{2} \mathrm{O}$ & 13 & 0 & 10 & 1 & 900 & 800 \\
\hline $\mathrm{SO}_{2}$ & n.d. & n.d. & 34 & 0 & 200 & 200 \\
\hline $\mathrm{H}_{2} \mathrm{~S}$ & n.d. & n.d. & 19 & 0 & 130 & 100 \\
\hline $\mathrm{S}_{2}$ & n.d. & n.d. & 18 & 0 & 100 & 0 \\
\hline $\mathrm{F}$ & 0 & 0 & 10 & 0 & 40 & 30 \\
\hline $\mathrm{Cl}$ & 0 & 0 & 0 & 0 & 1.8 & 1.2 \\
\hline
\end{tabular}

${ }^{1}$ Gas species based on SIMS measurements of $\mathrm{H}, \mathrm{C}, \mathrm{S}, \mathrm{F}$ and $\mathrm{Cl}$ and calculated as ppm (wt) of the species indicated as present in the gas phase (Fig. 3). S in the gas phase is assumed equally as $\mathrm{SO}_{2}$ (Fogel and Rutherford 1995), $\mathrm{H}_{2} \mathrm{~S}$ and $\mathrm{S}_{2}$ (Galliard and Scaillet 2009). Melt inclusion data indicate as much as 50 ppm of S present initially was lost in Stage 2; 300 ppm S was lost in Stage 3. n.d. = not determined. 


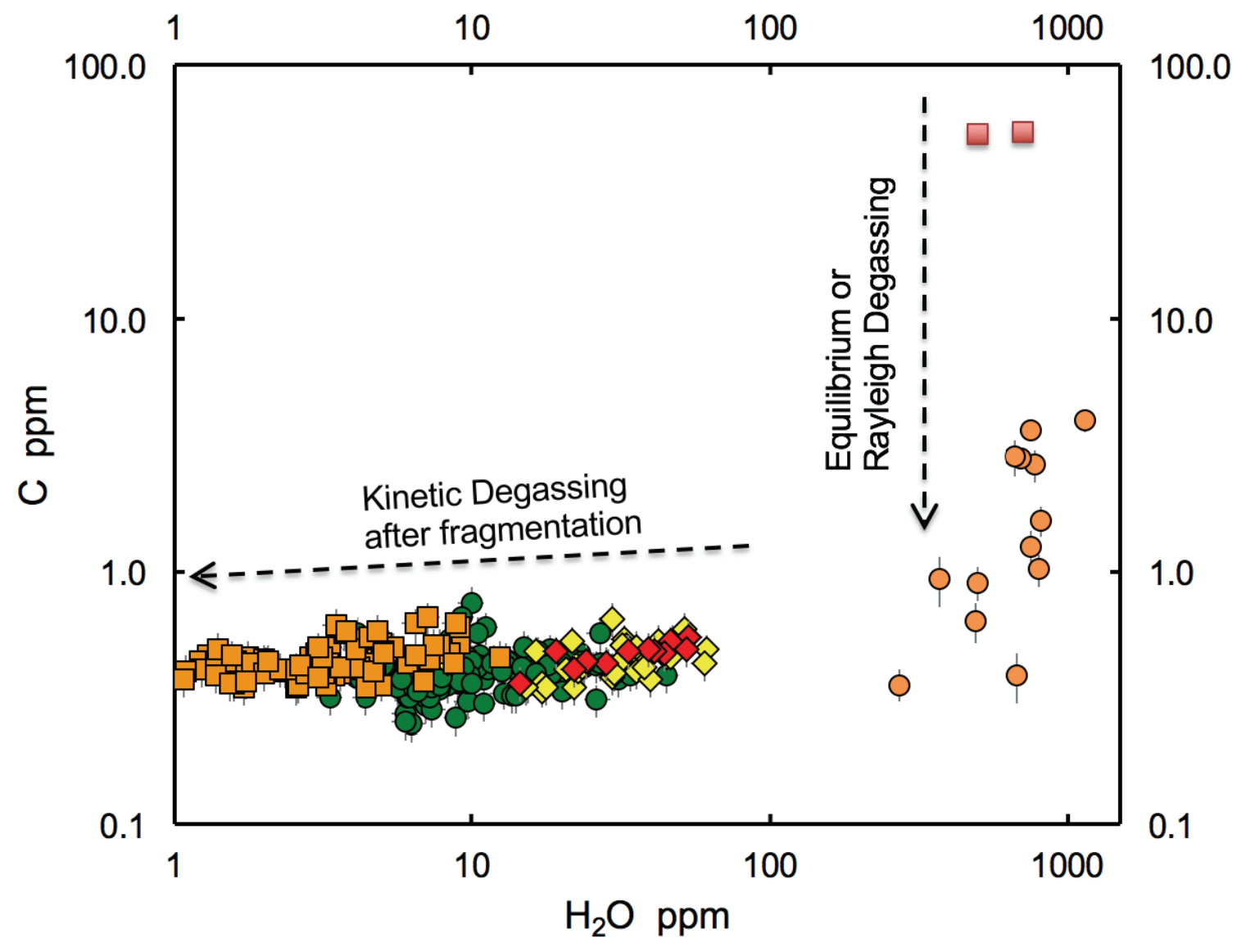

Figure 1. 


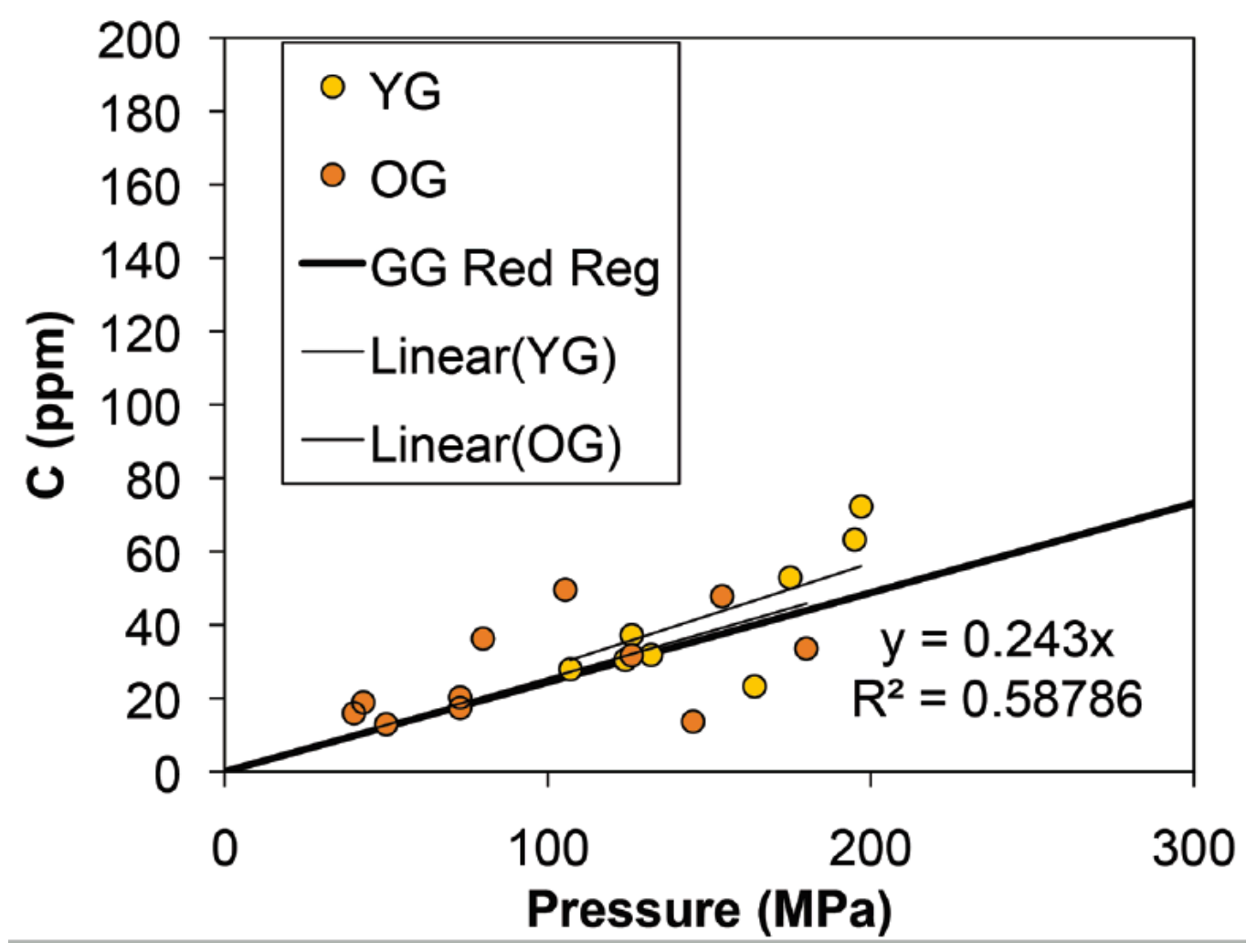

Figure 2 


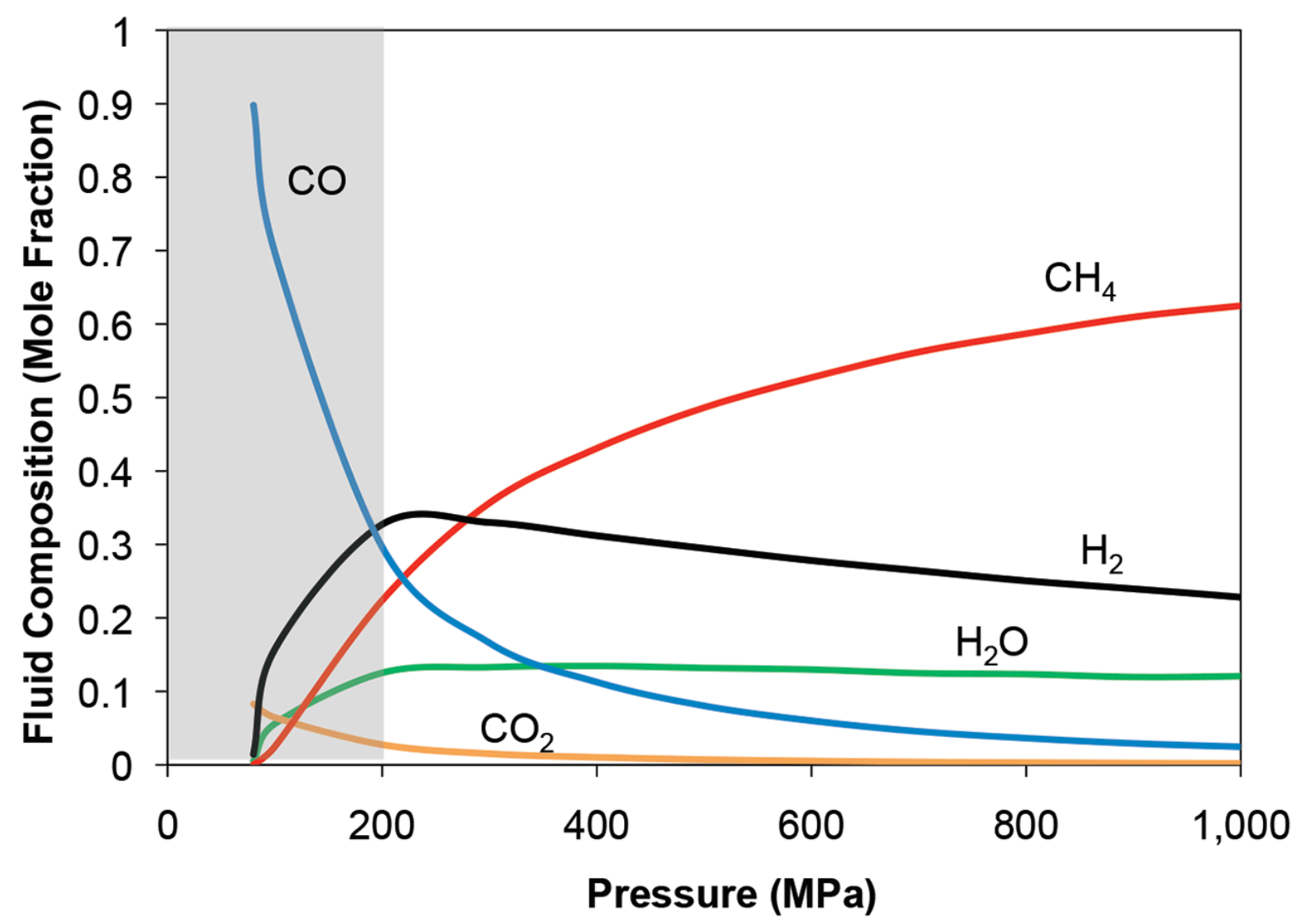

Figure 3. 


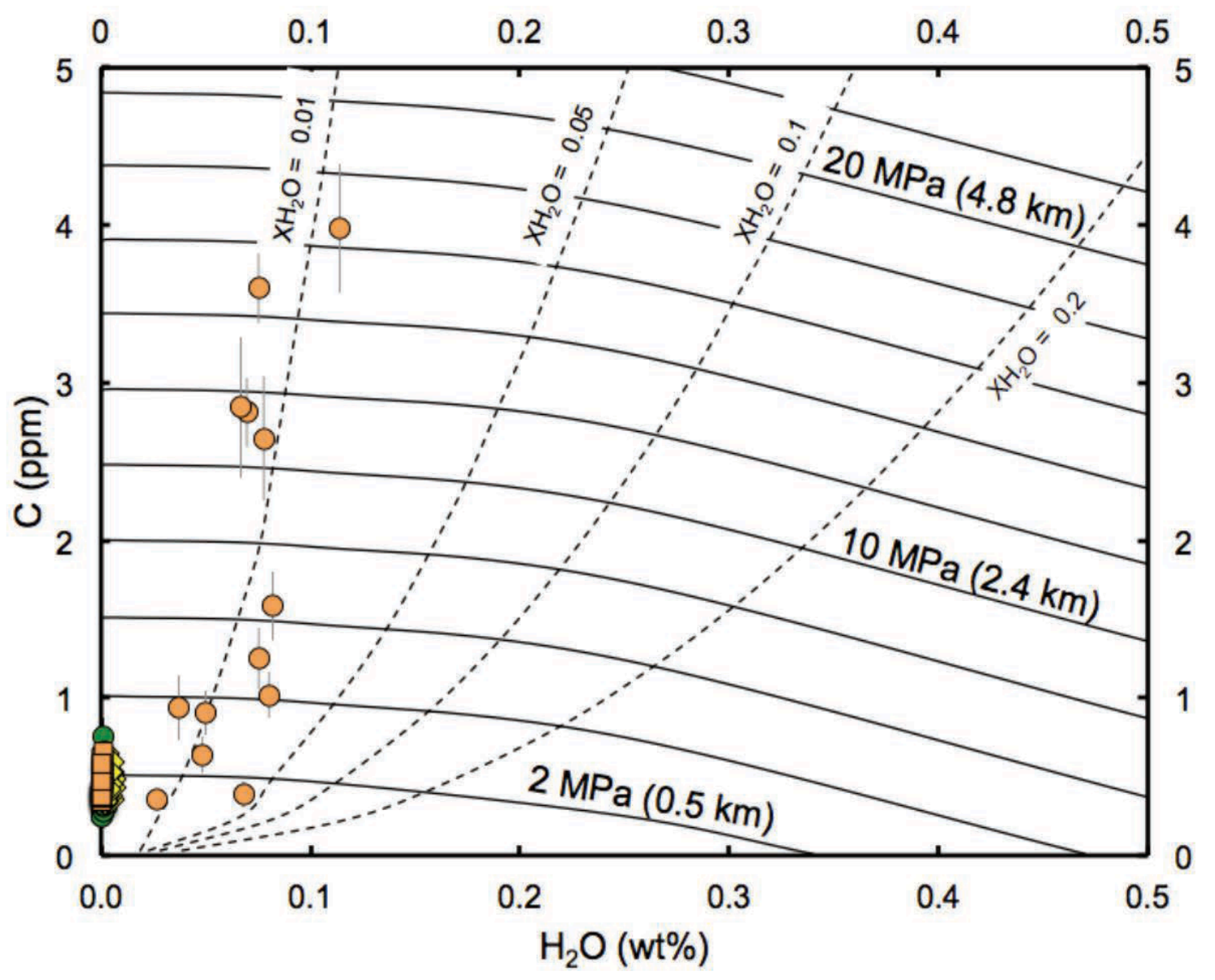

Figure 4. 

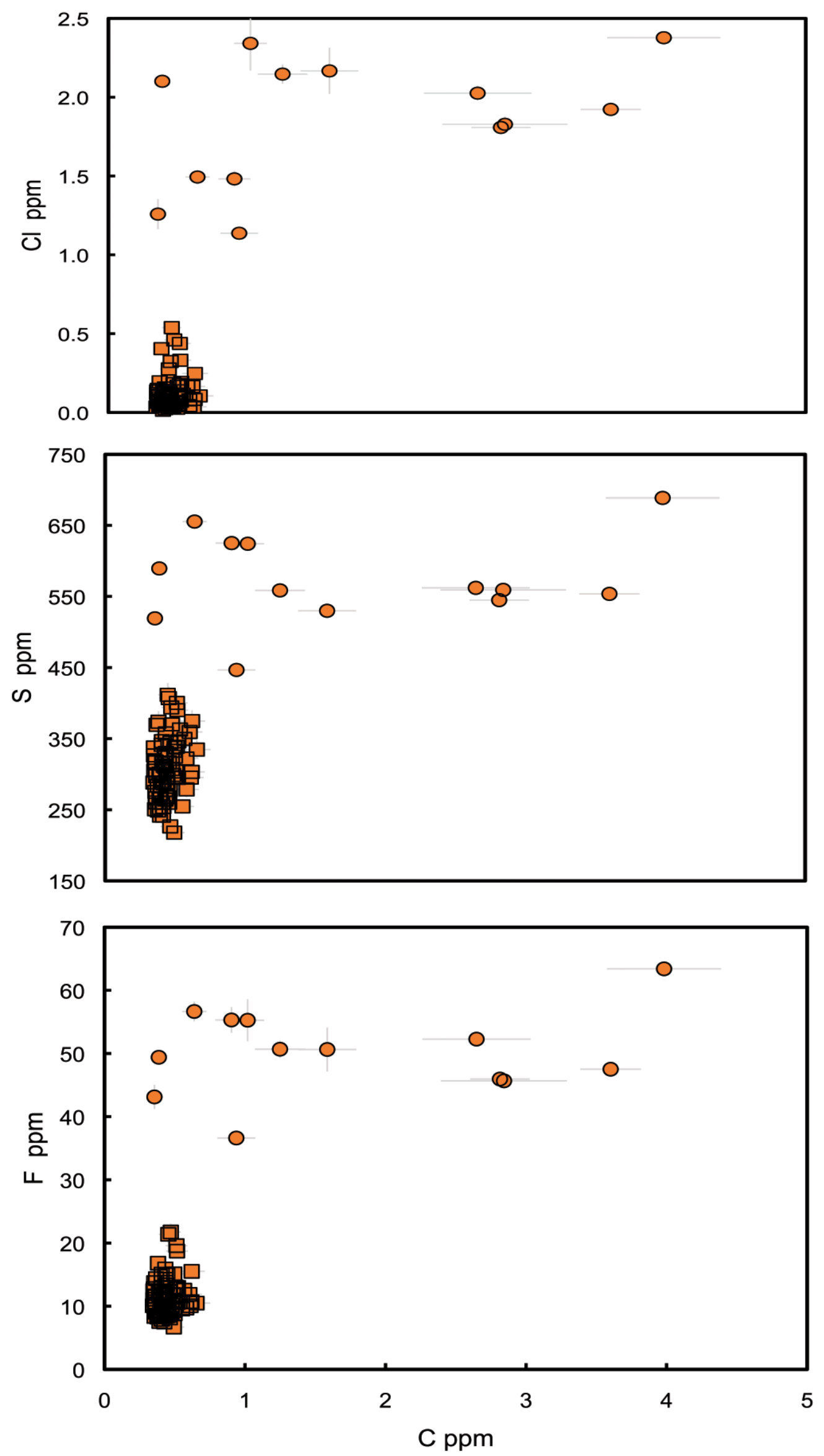

Fig. 5 


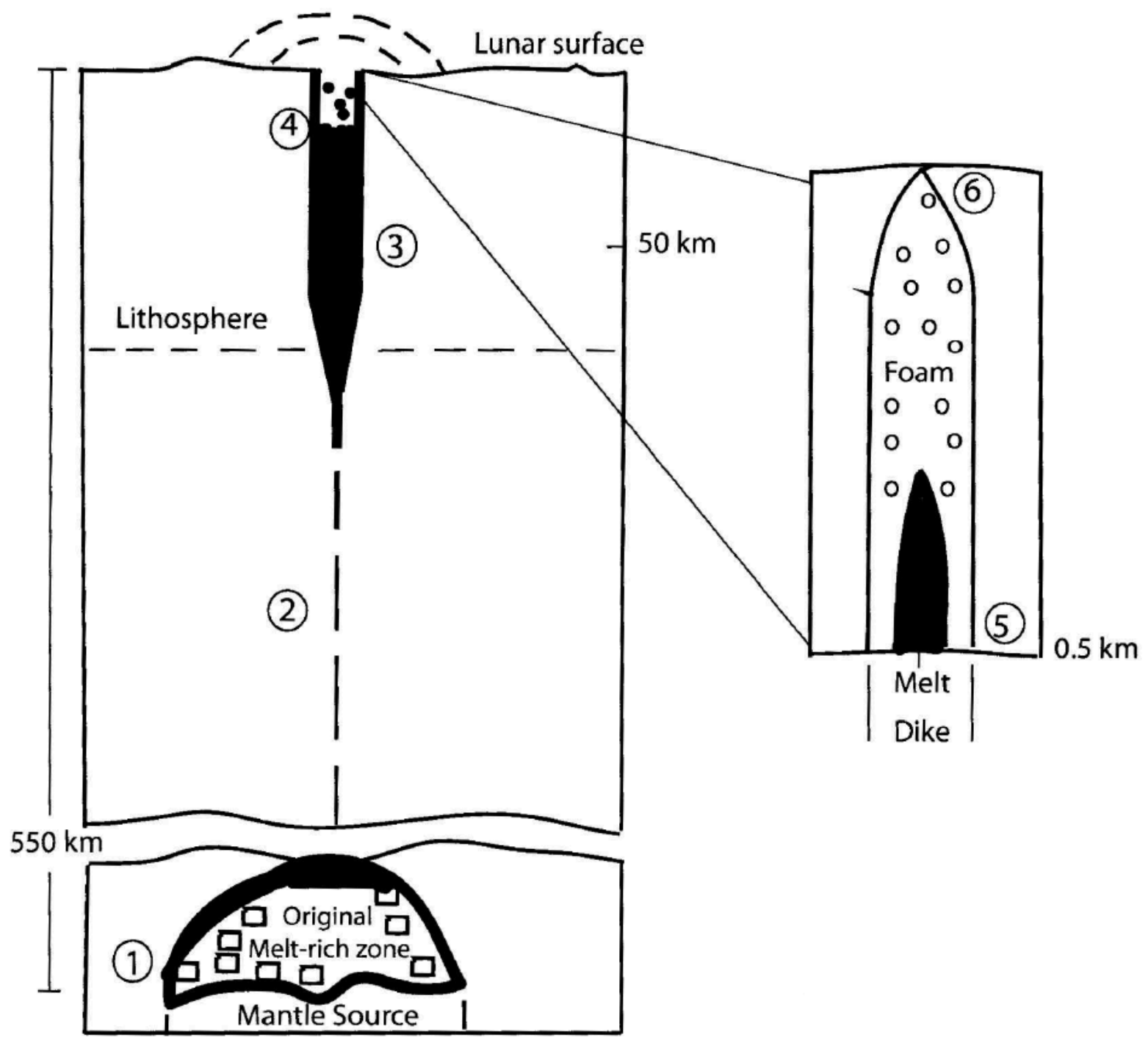

Figure 6. 